\title{
Development and Validation of UV Spectroscopic First Derivative Method for Simultaneous Estimation of Dapagliflozin and Metformin Hydrochloride in Synthetic Mixture
}

\author{
Jani BR , Shah KV and Kapupara PP
}

School of Pharmacy, RK University, Kasturbadham, Rajkot, Gujarat, India

*Corresponding author: Jani BR, School of Pharmacy, RK University, Kasturbadham, Rajkot, Gujarat, India, E-mail: bhavik.jani92@gmail.com

Citation: Jani BR, Shah KV, Kapupara PP (2015) Development and Validation of UV Spectroscopic First Derivative Method for Simultaneous Estimation of Dapagliflozin and Metformin Hydrochloride in Synthetic Mixture. J Bioequiv 1(1): 102. doi: 10.15744/2575-551X.1.102

Received Date: February 19, 2015 Accepted Date: September 02, 2015 Published Date: September 04, 2015

\begin{abstract}
The Novel, simple, sensitive, rapid, accurate and economical and reliable First derivative spectroscopic method has been developed for synthetic mixture of Dapagliflozin (DAPA) and Metformin hydrochloride (MET). This method involve solving of first derivative method based on measurement of absorbance at two wavelengths $235 \mathrm{~nm}$ and $272 \mathrm{~nm}$ using UV visible spectrophotometer with $1 \mathrm{~cm}$ matched quartz cells and methanol solvent were employed in this method. The Developed method obeyed Beer's-Lambert's law in the concentration range of $0.5-2.5 \mu \mathrm{g} / \mathrm{ml}$, having correlation coefficient for Dapagliflozin was 0.984 and $25-125 \mu \mathrm{g} / \mathrm{ml}$, having correlation coefficient for Metformin hydrochloride was 0.982. A derivative spectrum shows better resolution of overlapping bands than the fundamental spectrum. Different validation parameters like, precision (intra-day and inter-day studies), limit of detection, limit of quantitation were studied and were found to be within the limit. Results of the methods were validated statistically.The validation results showed that the proposed method was sensitive, economical and simple and it could be successfully applied for evaluation and to estimate the amount of synthetic mixture containing Dapagliflozin and Metformin hydrochloride.
\end{abstract}

Keywords: Dapagliflozin; Metformin hydrochloride; Antidiabetic; UV spectroscopy; First derivative method

\section{Introduction}

Dapagliflozin is a crystalline solid. Dapagliflozin is inhibiting renal glucose reabsorption through the solid-glucose cotranspoter (SGLT) offers an insulin-independent alternative to controlling blood glucose concentrations in patients with type 2 diabetes. Dapagliflozin is a first generation, selective SGLT inhibitor that blocks glucose transport with about 100 -fold selective for SGLT 2 over SGLT 1 [1].

Metformin is an oral anti-diabetic drug in the biguanide class. It is the first-line drug of choice for the treatment of type 2 diabetes, particularly in overweight and obese people. Evidence is also mounting for its efficacy in gestational diabetes, although safety concerns still preclude its widespread use in this setting. It activates the AMP-activated protein kinase (AMPK). It is also used in the treatment of polycystic ovary syndrome and has been investigated for other diseases where insulin resistance may be an important factor [2].

The first derivative spectrum is a plot of the rate of change of absorbance with wavelength against wavelength, i.e. a plot of the slope of the fundamental spectrum against wavelength or a plot of $\mathrm{dA} / \mathrm{d} \lambda$ vs $\lambda$. The first derivative derivative spectrum of an absorption band is characterized by a maximum, a minimum and a cross over point at the $\lambda_{\max }$ of the absorption band.

These spectral transformations confer two principle advantages on derivative spectrophotometry. Firstly, an even order spectrum is of narrower spectral bandwidth than its fundamental spectrum. A derivative spectrtum shows better resolution of overlapping bands than the fundamental spectrum. Secondly, this discriminates in favor of substances of narrow spectral bandwidth against broad bandwidth substances. Substances of narrow spectral bandwidth display larger derivative amplitudes than those of broad bandwidth substances [3].

Literature survey reveals that few HPLC [4-6], LC MS methods [6-8], Spectrophotometry [9,10], First derivative methods [11,12] have been reported for determination of Metformin hydrochloride in formulations and LC-MS method reported for Dapagliflozin in rat plasma [13] and UV spectroscopy method [14]. There is no any single UV method reported for simultaneous analysis of Dapagliflozin and Metformin hydrochloride. A successful attempt has been made to estimate two drugs simultaneously by first derivative spectroscopy. The objective of the investigation is to develop and validate an analytical method for the estimation of Dapagliflozin and Metformin hydrochloride in a combined mixture by first derivative spectroscopic method. 


\section{Materials and Methods}

\section{Chemicals and Reagent}

Dapagliflozin was obtained as a gift sample from Manus akkteva, Ahmedabad and Metformin hydrochloride was obtained as a gift sample Aarti Drugs, Mumbai. Methanol was purchased from Merck laboratories.

\section{Instrumentation}

A double beam UV/Visible spectrophotometer (Labtronic-LT2900) was employed with spectral bandwidth of $1 \mathrm{~nm}$ and wavelength accuracy of $\pm 0.3 \mathrm{~nm}$ with automatic wavelength correction with a pair of $10 \mathrm{~mm}$ quartz cells. A Shimadzu electronic analytical balance (BL-220H) was used for weighing the sample.

\section{Preparation of stock solution and Calibration Curve}

$10 \mathrm{mg}$ each of Dapagliflozin and Metformin hydrochloride were weighed separately and transferred in two different $100 \mathrm{ml}$ volumetric flasks. Both the drugs were dissolved in $50 \mathrm{ml}$ of methanol by vigorous shaking and then volume was made upto the mark with methanol to obtain final concentration of $100 \mu \mathrm{g} / \mathrm{ml}$ of each component.

\section{Selection of Analytical Wavelength}

Using appropriate dilutions of the standard stock solution, the solutions were scanned separately in the wavelength region of 400-190 nm. The absorbance spectra, thus obtained were derivatized to remove the interference of absorbing species. The two wavelengths selected should be such that at each wavelength the absorbance difference between the components should be as large as possible. From the examination of the overlay first derivative spectra of DAPA and MET, $235 \mathrm{~nm}\left(\lambda_{1}\right)$ and 272 $\mathrm{nm}\left(\lambda_{2}\right)($ Table 1,2) were selected as working wavelengths for the first derivative spectroscopy (Figure 1,2 and 3), as at 235.0 nm DAPA is exhibited zero absorbance and at $272.0 \mathrm{~nm}$ MET showed zero absorbance.

\begin{tabular}{|c|c|c|}
\hline Sr. No. & Concentration $(\boldsymbol{\mu g} / \mathbf{m l})$ & First derivative at $\mathbf{2 3 5} \mathbf{~ n m}$ \\
\hline 1 & 0.5 & -0.003 \\
\hline 2 & 1 & -0.006 \\
\hline 3 & 1.5 & -0.01 \\
\hline 4 & 2 & -0.012 \\
\hline 5 & 2.5 & -0.014 \\
\hline
\end{tabular}

${ }^{*}=$ mean absorbance of three absorbance

Table 1: Data for Standard Calibration Curve of Dapagliflozin at $235 \mathrm{~nm}$

\begin{tabular}{|c|c|c|}
\hline Sr. No. & Concentration $(\boldsymbol{\mu g} / \mathbf{m l})$ & First derivative at $\mathbf{2 7 2} \mathbf{~ n m}$ \\
\hline 1 & 25 & -0.005 \\
\hline 2 & 50 & -0.007 \\
\hline 3 & 75 & -0.011 \\
\hline 4 & 100 & -0.013 \\
\hline 5 & 125 & -0.015 \\
\hline
\end{tabular}

* $=$ mean absorbance of 3 absorbance

Table 2: Data for Standard Calibration Curve of Metformin $\mathrm{HCl}$ at 272 $\mathrm{nm}$ in methanol Solution

\section{Selection of Analytical Concentration Range}

For each drug appropriate aliquots were pipetted out from the standard stock solutions of DAPA into series of $10 \mathrm{ml}$ volumetric flasks. The volume was made upto the mark with methanol to get a set of solutions having the concentration $0.5,1,1.5,2,2.5 \mu \mathrm{g} /$ $\mathrm{ml}$ for Dapagliflozin and 25, 50,75,100,125 $\mu \mathrm{g} / \mathrm{ml}$ for Metformin hydrochloride. The absorbance of each of these solutions were measured at the selected wavelengths (for DAPA at $235.0 \mathrm{~nm}$ and for MET at $272.0 \mathrm{~nm}$ ) and plotted against concentration. The concentration range over which the drugs obeyed Beer's law was chosen (Figure 4, 5 and 6 ). The range was found to be 0.5 to $2.5 \mu \mathrm{g} /$ $\mathrm{ml}$ for Dapagliflozin and 25 to $125 \mu \mathrm{g} / \mathrm{ml}$ for Metformin hydrochloride. The working curve equation was found to be $\mathrm{y}=-0.0004 \mathrm{x}$ +0.0004 with a correlation coefficient $\left(\mathrm{r}^{2}\right)$ value of 0.984 for DAPA and $\mathrm{y}=-0.0001 \mathrm{x}-0.0024$ with a correlation coefficient $\left(\mathrm{r}^{2}\right)$ value of 0.982 for MET.

\section{Development of First derivative method for Dapagliflozin and Metformin $\mathrm{HCl}$}

The concentration of $\mathrm{C}_{\mathrm{DAPA}}$ and $\mathrm{C}_{\mathrm{MET}}$ can be obtained from calibration curve. 


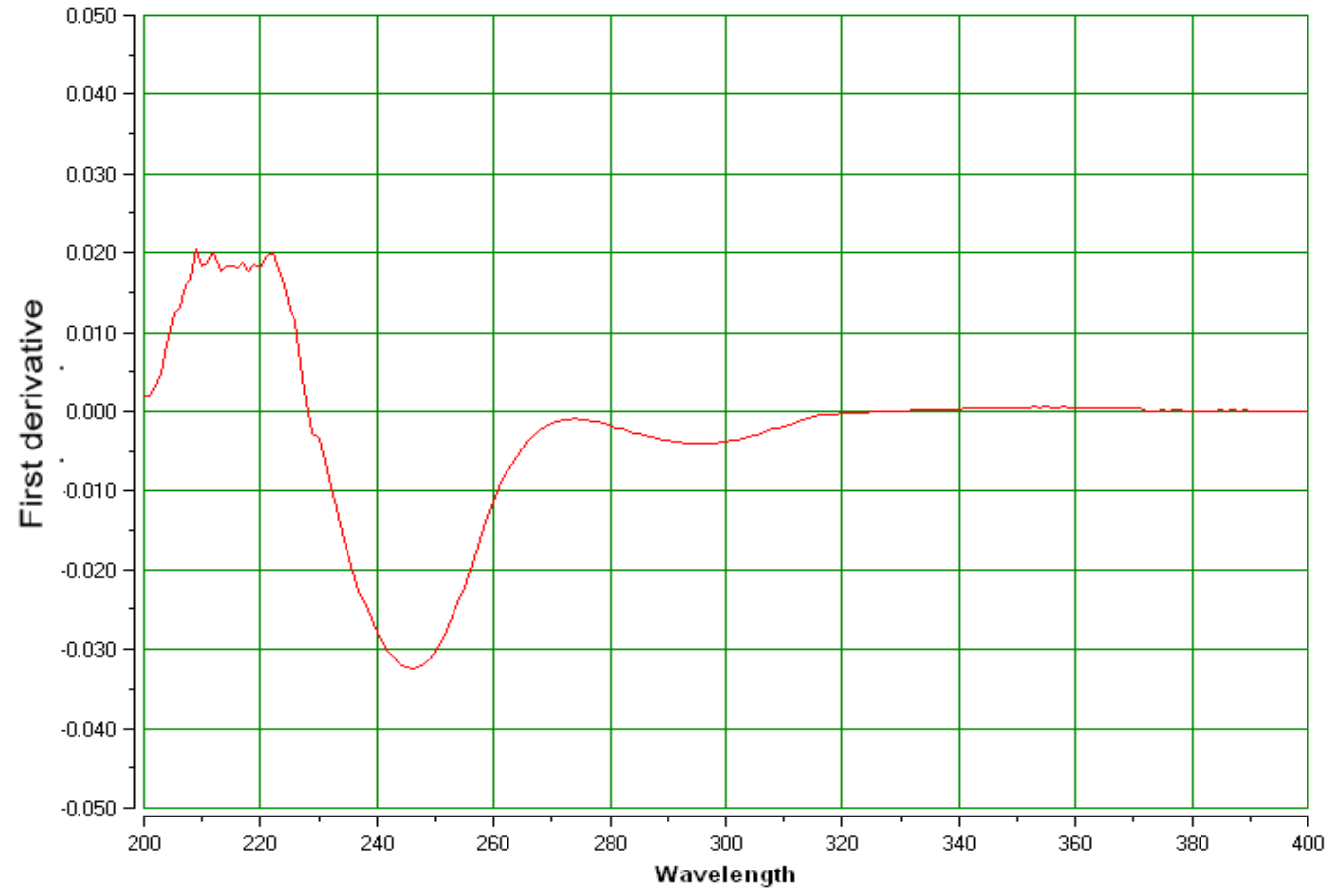

Figure 1: First derivative UV Spectrum of Dapagliflozin

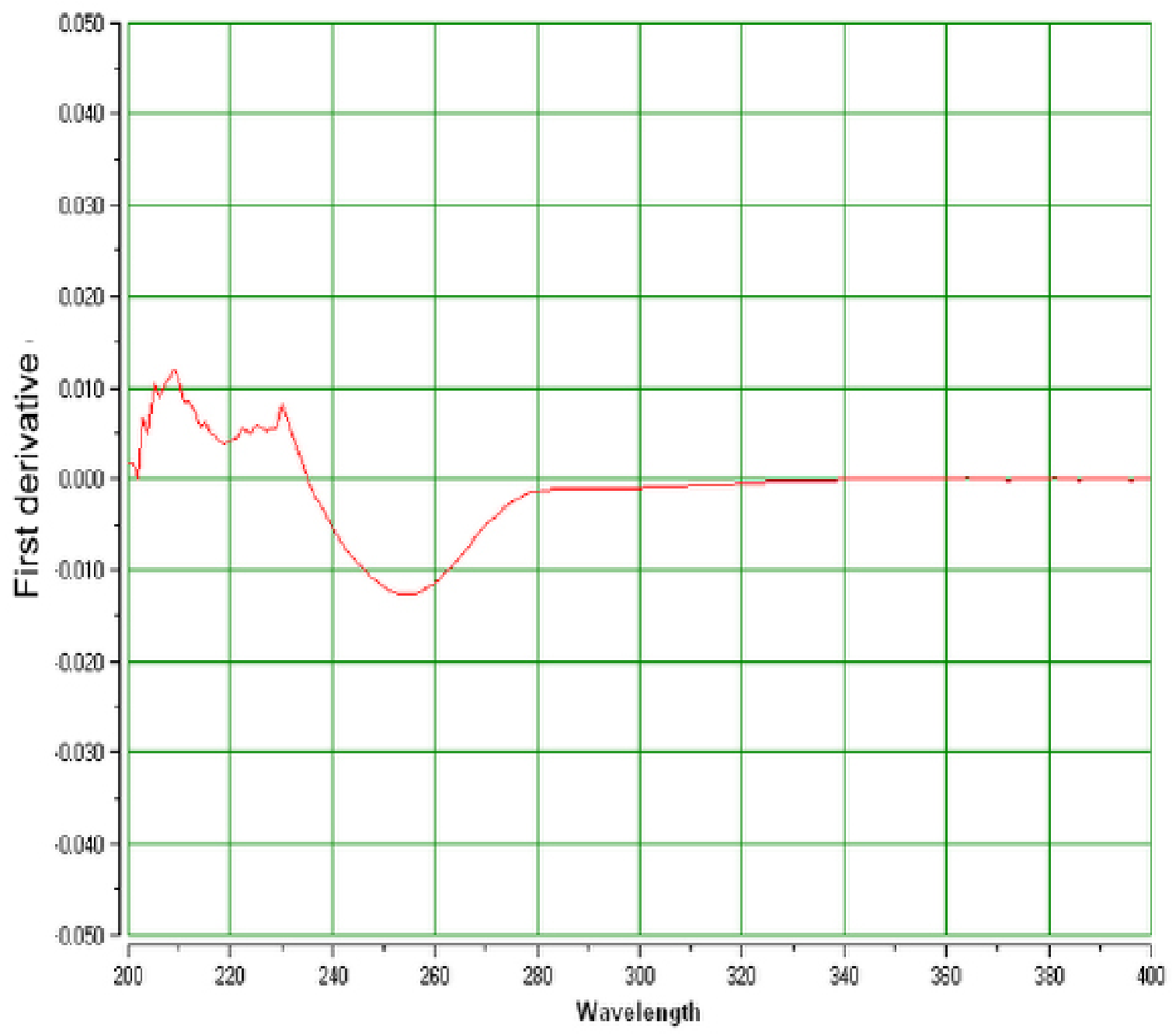

Figure 2: First dervivative UV Spectrum of Metformin $\mathrm{HCl}$ 


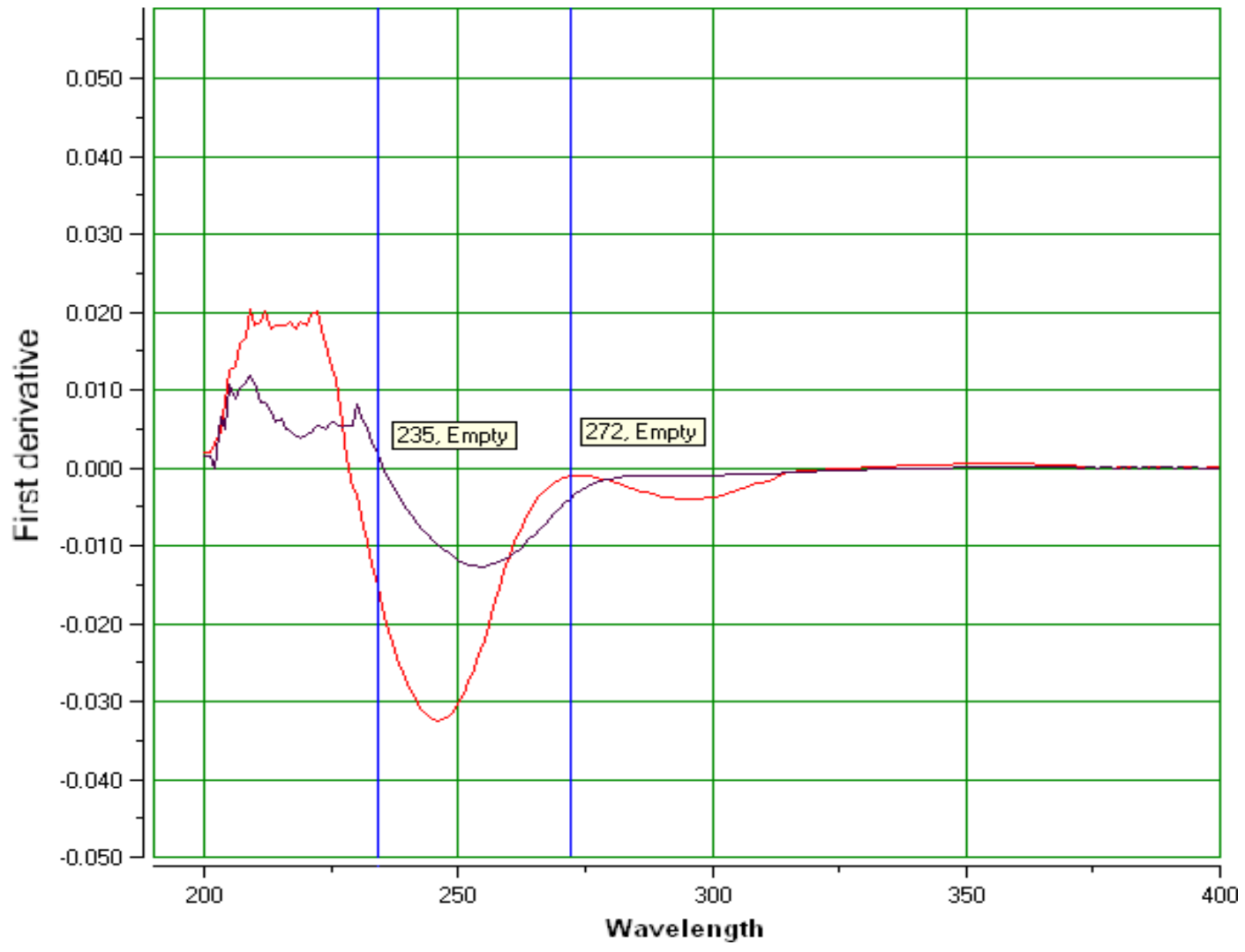

Figure 3: First derivative UV spectrum of Overlay of Dapagliflozin and Metformin HCl

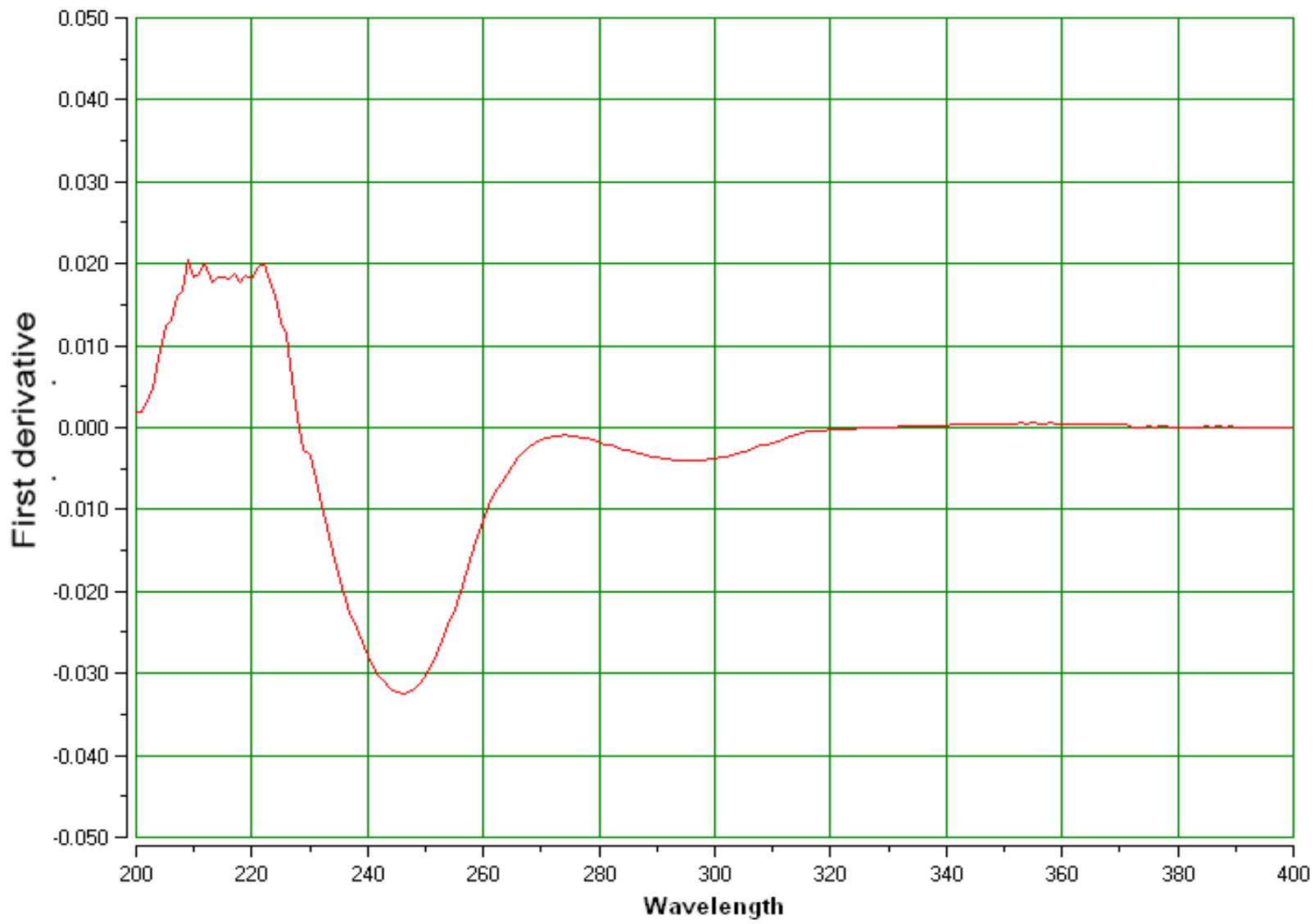

Figure 4: First derivative UV spectrum of powder mixture of Dapagliflozin and Metformin $\mathrm{HCl}$ 


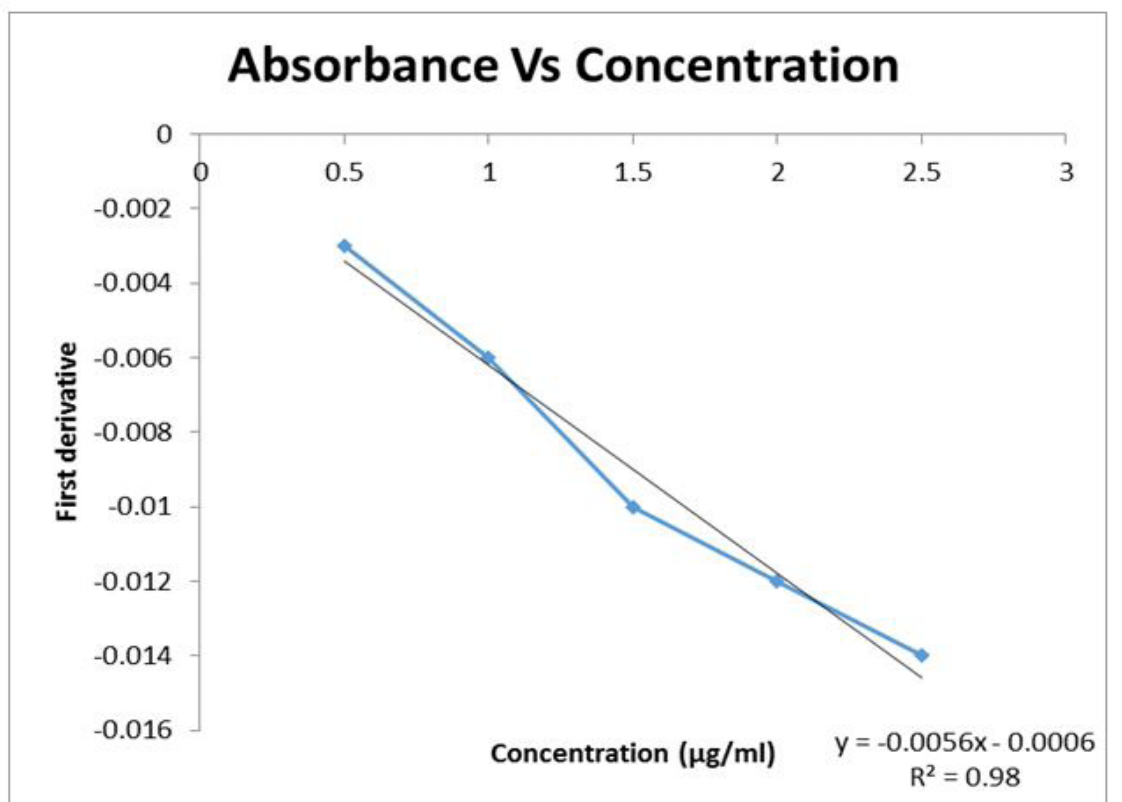

Figure 5: Calibration Curve of Dapagliflozin at $235 \mathrm{~nm}$ in Methanol Solution within the range of 0.5 to $2.5 \mu \mathrm{g} / \mathrm{ml}$ the drug obeyed Beer's law

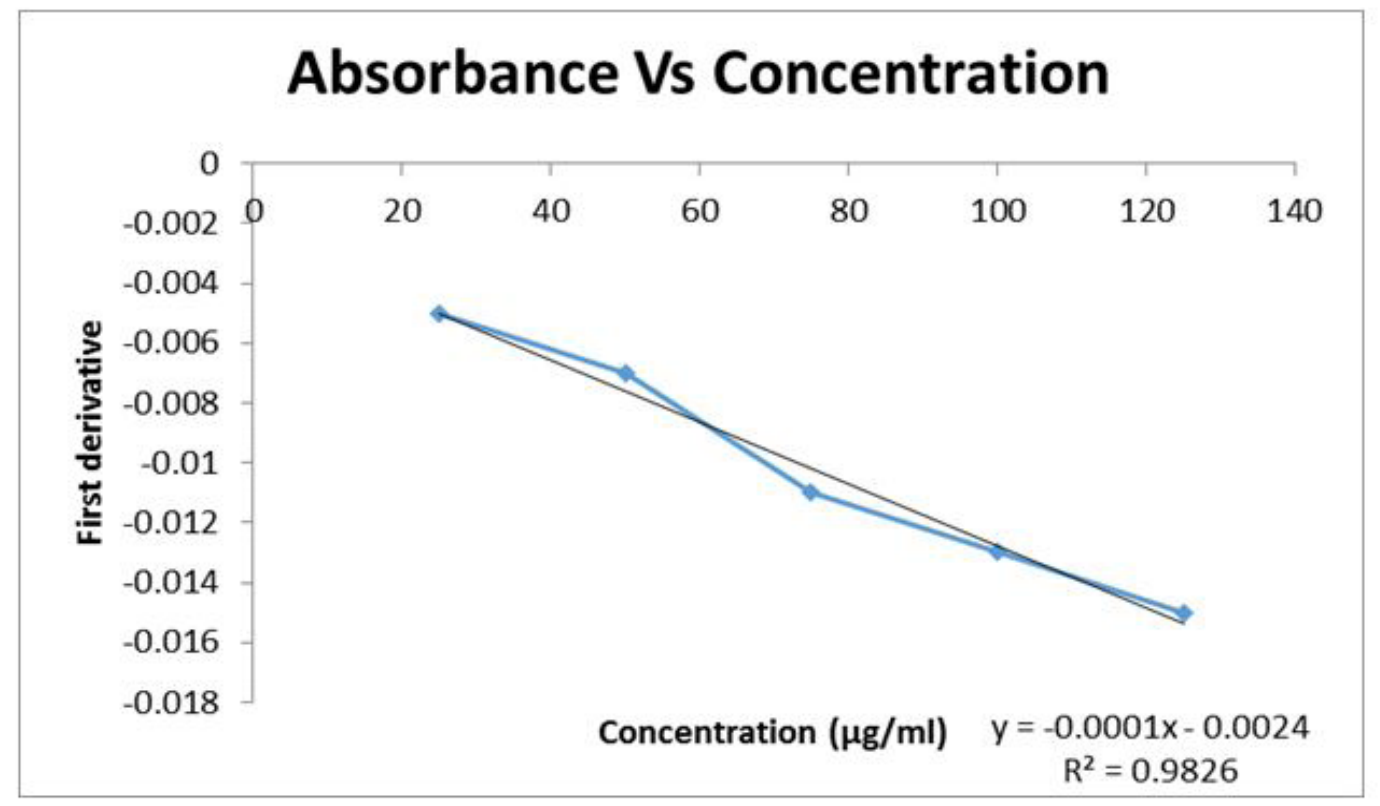

Figure 6: Calibration Curve of Metformin $\mathrm{HCl}$ at $272 \mathrm{~nm}$ in Methanol Solution Within the range of 25 to $125 \mu \mathrm{g} / \mathrm{ml}$ the drug obeyed Beer's law

\section{Validation study}

The following method parameters were evaluated in order to validate the quality of the proposed method: linearity, recovery, precision. Linear range of the proposed method was established by analysis of five standard calibration solutions. Recoveries were calculated using the slope of the linear regression. The intra and inter-day precision were evaluated by repeating the assay method three times (five replicates each time) on the same day and on three consecutive days (five replicates each day), respectively.

\section{Accuracy and Precision}

The accuracy study was performed by addition of known amounts of DAPA and MET to known concentration (addition method). Precision of the method were assessed by intra and inter-day validation. The intra and inter-day precision were determined by determining the concentrations of DAPA and MET in synthetic mixture in five replicates for three different concentration levels. The intra and inter-day precision were obtained by repeating the assay method three times on the same day and on three consecutive days, respectively. The repeatability of the method was expressed as the \%RSD. Accuracy was expressed as the percent deviation of the mean determined concentration against the spiked concentration. (Table 3), summarizes the mean values of accuracy and precision for both intra and inter-day assays. Both precision and accuracy results indicated satisfactory precision of the proposed methods according to the FDA guidelines. 


\begin{tabular}{|c|c|c|}
\hline Parameter & Dapagliflozin & Metformin $\mathrm{HCl}$ \\
\hline Working $\lambda$ & 235 & 272 \\
\hline Beer's Law range & $0.5-2.5 \mu \mathrm{g} / \mathrm{ml}$ & $25-125 \mu \mathrm{g} / \mathrm{ml}$ \\
\hline Regression Values: & & \\
\hline i. Slope & -0.0056 & -0.0001 \\
\hline ii. Intercept & -0.0006 & -0.0024 \\
\hline $\begin{array}{c}\text { iii. Regression coef- } \\
\text { ficient }\left(\mathrm{r}^{2}\right)\end{array}$ & 0.980 & 0.982 \\
\hline
\end{tabular}

Table 3: Regression and Optical Characteristics of Dapagliflozin and Metformin $\mathrm{HCl}$

\section{Calibration curve}

The calibration curves showed a good linearity in the concentration range of $0.5-2.5 \mu \mathrm{g} / \mathrm{ml}$ and $25-125 \mu \mathrm{g} / \mathrm{ml}$ with correlation coefficient $\left(\mathrm{r}^{2}>0.984\right.$ and 0.982$)$ respectively for Dapagliflozin and Metformin hydrochloride (Table 4). The Limit of Detection (LOD) and Limit of Quantification (LOQ) values for Dapagliflozin and Metformin hydrochloride were determined according to ICH recommendations [15] considering the SD of the response and the slope.

\begin{tabular}{|c|c|c|}
\hline Drug & LOD $(\mu \mathrm{g} / \mathrm{ml})$ & LOQ $(\boldsymbol{\mu g} / \mathbf{m l})$ \\
\hline DAPA $(235 \mathrm{~nm})$ & 0.009 & 0.039 \\
\hline MET $(272 \mathrm{~nm})$ & 0.013 & 0.041 \\
\hline
\end{tabular}

Table 4: Data for LOD and LOQ of Dapagliflozin and Metformin hydrochloride

\section{Standardization of the method by analysis of powder mixture of known composition}

The mixture of Dapagliflozin and Metformin $\mathrm{HCl}$ having concentration of $1 \mu \mathrm{g} / \mathrm{ml}$ of DAPA and $50 \mu \mathrm{g} / \mathrm{ml}$ of MET were analyzed by preparing a solution of suitable dilution in Methanol solution. The absorbance of the solution at $235 \mathrm{~nm}$ and $272 \mathrm{~nm}$ for both drugs were measured. From the calibration curve concentration of Dapagliflozin and Metformin $\mathrm{HCl}$ respectively in Methanol solution could be measured Table 5, 6 and 7 .

\begin{tabular}{|c|c|c|c|c|c|c|}
\hline \multirow{2}{*}{ Sr. No. } & \multicolumn{2}{|c|}{ Amount present in $\mu \mathrm{g} / \mathrm{ml}$} & \multicolumn{2}{|c|}{ Amount found in $\mu \mathrm{g} / \mathrm{ml}$} & \multicolumn{2}{|c|}{ Amount found in \% } \\
\hline & DAPA & MET & DAPA & MET & DAPA & MET \\
\hline 1 & 1 & 50 & 0.99 & 50.57 & 99 & 101.14 \\
\hline 2 & 1 & 50 & 1.01 & 49.28 & 101 & 98.56 \\
\hline 3 & 1 & 50 & 0.98 & 48.85 & 98 & 103.7 \\
\hline 4 & 1 & 50 & 1.02 & 50.71 & 102 & 101.42 \\
\hline 5 & 1 & 50 & 0.98 & 50.01 & 98 & 100 \\
\hline
\end{tabular}

\begin{tabular}{|c|c|c|c|c|c|}
\hline $\begin{array}{c}\text { Name of } \\
\text { Component }\end{array}$ & $\begin{array}{l}\text { Amount Present } \\
\qquad(\mu \mathrm{g} / \mathrm{ml})\end{array}$ & Mean $^{\star}$ & $\begin{array}{l}\text { Standard } \\
\text { Deviation }\end{array}$ & $\begin{array}{l}\% \text { Co-efficient } \\
\text { of Variation }\end{array}$ & $\begin{array}{c}\text { Standard } \\
\text { Error of Mean }\end{array}$ \\
\hline DAPA & 1 & 99.6 & 1.817 & 1.824 & 0.812 \\
\hline MET & 50 & 100.16 & 1.906 & 1.904 & 0.849 \\
\hline
\end{tabular}

The \%R.S.D. is less than $2 \%$ as required by USP and ICH guidelines

\begin{tabular}{|c|c|c|c|c|c|c|c|c|}
\hline \multirow{2}{*}{$\begin{array}{c}\text { Level of \% } \\
\text { Recovery }\end{array}$} & \multicolumn{2}{|c|}{ \% Mean Recovery } & \multicolumn{2}{c|}{ Standard Deviation } & \multicolumn{2}{c|}{ Co-efficient of Variation* (\% R.S.D.) $^{\text {Standard Error }}$} \\
\cline { 2 - 9 } & DAPA & MET & DAPA & MET & DAPA & MET & DAPA & MET \\
\hline 80 & 98.15 & 99.95 & 0.851 & 0.061 & 0.867 & 0.061 & 0.491 & 0.035 \\
\hline 100 & 99.66 & 99.34 & 0.763 & 0.373 & 0.766 & 0.375 & 0.441 & 0.215 \\
\hline 120 & 99.08 & 99.72 & 0.457 & 0.163 & 0.461 & 0.164 & 0.264 & 0.094 \\
\hline
\end{tabular}

Table 7: Statistical Validation for Recovery Studies 


\section{Procedure for Precision}

In intraday precision sample having concentration of $1 \mu \mathrm{g} / \mathrm{ml}$ of DAPA and $50 \mu \mathrm{g} / \mathrm{ml}$ of MET were scanned six times at different time interval in the same day. Interday precision was obtained by the assay of six sample sets on different days. The results are shown in Table 8 and 9.

\begin{tabular}{|c|c|c|c|c|}
\hline Drug & ${\text { \% } \text { Mean }^{*}}^{*}$ & S.D $^{*}$ & \% R.S.D. $^{*}$ & S.E. $^{*}$ \\
\hline DAPA & 99.02 & 0.759 & 0.760 & 0.339 \\
\hline MET & 99.54 & 0.397 & 0.399 & 0.171 \\
\hline${ }^{*}=6$
\end{tabular}

Table 8: Intra-day Precision

The standard deviation (S.D.), relative standard deviation (\%R.S.D.) and standard error (S.E.) calculated are low, indicating high degree of precision of the method. The \%R.S.D. is less than $2 \%$ as required by USP and ICH guidelines.

\begin{tabular}{|c|c|c|c|c|}
\hline Drug & \% Mean $^{*}$ & S.D $^{*}$ & \% R.S.D. $^{*}$ & S.E. $^{*}$ \\
\hline DAPA & 98.98 & 0.920 & 0.929 & 0.411 \\
\hline MET & 99.87 & 0.235 & 0.235 & 0.105 \\
\hline${ }^{*} \mathrm{n}=6$
\end{tabular}

Table 9: Inter-day Precision

\section{Results}

The standard deviation (S.D.), relative standard deviation (\%R.S.D.) and standard error (S.E.) calculated are low, indicating high degree of precision of the method. The \%R.S.D. is less than $2 \%$ as required by USP and ICH guidelines.

\section{Discussion}

Proposed method for first derivative estimation of Dapagliflozin and Metformin $\mathrm{HCl}$ in combined sample solutions was found to be simple, accurate and reproducible. Table 3 shows data for optical characteristics. Data for validation and precision studies are given in Table 7, 8 and 9. Once the equations are determined, analysis required only the measuring of the absorbances of the sample solution at the two wavelengths selected, followed by a few simple calculations.

The standard deviation (S.D.), relative standard deviation (\%R.S.D.) and standard error (S.E.) calculated are low, indicating high degree of precision of the method. The \%R.S.D. is less than $2 \%$ as required by USP and ICH guidelines complies in our method.

\section{Conclusion}

The method was successfully used to estimate the amount of Dapagliflozin and Metformin hydrochloride in synthetic mixture containing Dapagliflozin $1 \mathrm{mg}$ and $50 \mathrm{mg}$ of Metformin hydrochloride.

By observing validation parameters, method was found to be specific, accurate, precise, repeatable and reproducible. This method is simple in calculation, hence can be employed for routine analysis of synthetic mixture as well as dissolution testing.

\section{Acknowledgement}

The authors thank Manus akkteva, Ahmedabad and Aarti Drugs, Mumbai for supplying gift samples of Dapagliflozin and Pioglitazone hydrochloride respectively to carry out this work.

\section{References}

1. DrugBank: Dapagliflozin (DB06292).

2. DrugBank: Metformin (DB00331).

3. Beckett AH, Stanlake JB (1988) Practical pharmaceutical chemistry (4 ${ }^{\text {th }}$ Edition) CBS publishers and distributors, New Delhi, Part Two 281-307.

4. Patil SS, Bonde CG (2009) Development and Validation of analytical method for simultaneous estimation of Glibenclamide and Metformin $\mathrm{HCl}$ in bulk and tablets using UV visible spectroscopy. Int J ChemTech Re 1: 905-9.

5. Dhabale PN, Seervi CR (2010) Simultaneous UV Spectrophotometric method for estimation of Gliclazide and Metformin hydrochloride in tablet dosage form. Int J ChemTech Re 2: 813-7.

6. Sujana KP, Rani SG, Prasad MB, Reddy MS (2010) Simultaneous estimation of Pioglitazone Hydrochloride and Metformin hydrochloride using UV Spectroscopic method. J Biomed Sci and Res 2: 110-5.

7. Dadhania KP, Nadpara PA, Agrawal YA (2011) Development and validation of spectrophotometric method for simultaneous estimation of Gliclazide and Metformin hydrochloride in bulk and tablet dosage form by Simultaneous equation method. IJPSR 2: 1559-63.

8. Dhabale PN, Seervi CR (2010) Simultaneous UV Spectrophotometric method for estimation of Gliclazide and Metformin hydrochloride in tablet dosage form. Int J ChemTech Res 2: 813-7.

9. Shah AS, Sen DB, Sen AB (2011) Simultaneous UV Spectrophotometric Method for Estimation of Fenofibrate and Metformin Hydrochloride in Tablet Dosage Form. Asian J Resear in Chemistry 4: 1234-7.

10. Raj NP, Nargund RG, Kabra PS, Patel KA, Nargund LVG (2011) Simultaneous Quantification of Voglibose and Metformin by Validated Analytical Method in Tablet Dosage Form. Int J Institu Pharmacy and Life Scien 1: 58-63. 
11. Prasanth VG, Eapen SC, Kutty SV (2012) Development and validation of UV Spectroscopic Methods For the the simultaneous estimation of Ropaglinide and Metformin hydrochloride in synthetic mixture. J pharmaceu science and health care 2: 150-8.

12. Kumar SN, Huidrom S, Prasad VV (2012) Development and validation analytical methods for Simultaneous of Sitagliptin Phosphate and Metformin HCl in bulk and Tablets by using UV Spectroscopy. Int J pharmacy \& Industrial research 2: 299-307.

13. Lande NR, Shektar BM, Kadam SS and Dhaneshwar SR (2000) Simultaneous spectrophotometric estimation of Losartan potassium and Hydrochlorothiazide in tablet dosage form. Indian Drugs 37: 577-81.

14. Sanagapati M, Dhanalakshmi K, Reddy NG, Sreenivasa S (2014) Method development and validation of Dapagliflozin API by UV spectroscopy. Int J Pharm Sci rev 27: 270-2.

15. Aubry AF, Gu H, Magnier R, Morgan L, Xu X, et al. (2010) Validated LC-MS/MS methods for the determination of Dapagliflozin, a sodium-glucose co-transporter 2 inhibitor in normal and ZDF rat plasma. Bio analysis 2: 2001-9.

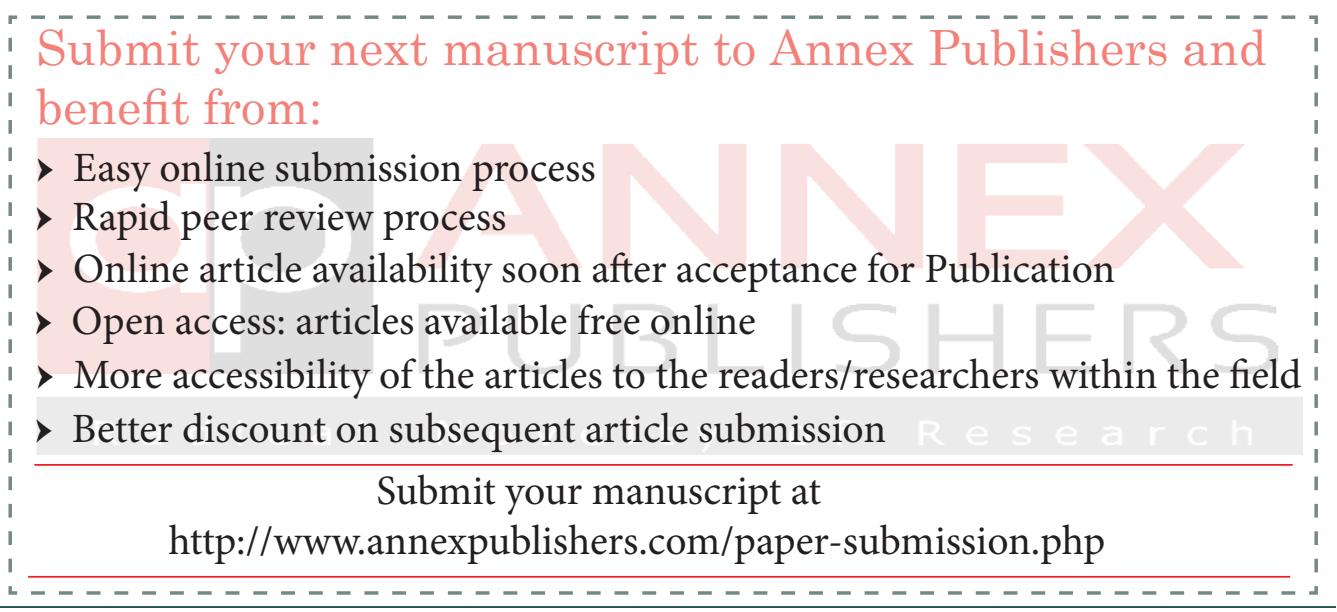

